\title{
PREVALENCE OF IRON DEFICIENCY IN THALASSEMIA TRAIT: A STUDY IN BSMMU, DHAKA
}

\author{
MUJAHIDA RAHMAN ${ }^{1}$, NASEEB MUHAMMAD IRSHADULLAH ${ }^{2}$, MUNIM AHMED $^{3}$, AMIN LUTFUL KABIR $^{4}$, \\ MASUDA BEGUM ${ }^{5}$, ABM GOLAM MOSTAFA ${ }^{6}$, ABED HUSSAIN KHAN ${ }^{7}$
}

\begin{abstract}
Background: Thalassemia is considered the most common genetic disorder worldwide and about 7\% of world populations are carriers. A vast majority of such cases have iron deficiency.

Objective: This study was undertaken to find out the pattern of iron status in thalassemia traits and thus to determine co-existing iron deficiency in them.

Method: This cross sectional study was carried out in the Department of Hematology, BSMMU, Dhaka from January 2007 to December 2007. Adult anemic patients of hypochromic microcytic blood film attending outpatient department were screened for thalassemia on the basis of clinical history, physical findings and hemoglobin electrophoresis. A total of 50 anemic patients with carrier state of thalassemia was detected and selected for evaluation of iron profile.

Results: Patients having iron deficiency detected by serum iron profile were compared with those without iron deficiency. The mean age in years of study subjects were $30.38 \pm 9.79$ years. Among the study population, 50\% were male and 50\% were female. Highest frequency of co-existent iron deficiency was found among the age of 21-30 years. Prevalence of iron deficiency was 30.2\% among $b$-thalassemia trait. A statistically significant mean difference of $H b, M C V, M C H, M C H C$, serum iron, TIBC, S. Ferritin, transferring saturation was found indicating study subjects without iron deficiency had higher level than with iron deficiency $(p<0.05)$.

Conclusion: Clinical iron deficiency may occur in thalassemia trait/carriers of inherited hemoglobin disorders. The combined state should always be suspected and iron supplements are often needed to improve the status of anemia.
\end{abstract}

Keywords: $\beta$-Thalassemia trait, Iron Deficiency anemia,

\section{Introduction}

The thalassemias are a heterogeneous group of genetic disorders of hemoglobin synthesis, all of which result from a reduced rate of production of one or more of the globin chains of haemoglobin ${ }^{1}$. Several types of thalassemias have been described and named according to the affected globin chain, the most common types of clinical importance being b, á, and äâ thalassaemia ${ }^{2}$. In Bangladesh, $\mathrm{Hb} \mathrm{E}$ disorders are prevalent, where single mutation in globin gene is responsible for both reduced production of b-gene product and $\mathrm{Hb} \mathrm{E}$ instead of $\mathrm{Hb} \mathrm{A}$. That is why it is called 'thalassemic hemoglobinopathy'.

Thalassemia is considered the most common genetic disorder worldwide ${ }^{3}$. The WHO estimates that about
$7 \%$ of world populations are carriers ${ }^{1} .300000-500000$ children are born each year with the severe homozygous states of this diseases ${ }^{2}$. The disease is highly prevalent in Mediterranean basin, Middle East, southern and eastern Asia, the south Pacific and south China with reported carrier rates ranging from $2 \%$ to $30 \%{ }^{1}$. In Bangladesh no definitive data regarding the carrier status of hereditary $\mathrm{Hb}$ disorders exist. A conservative World Health report estimates that 3\% of our populations are carriers of b-thalassemia which means that there are 3-6 million carrier of bthalassemia in Bangladesh. Affected births per thousand of b-thalassemia are $0.106^{4}$.

A microcytic hypochromic blood picture of the red cell is characteristic of thalassemia trait but the vast majority of such cases have iron deficiency anemia.

1 Medical Officer, Department of Hematology, BSMMU, Dhaka

2 Resident, Department of Hematology, BSMMU, Dhaka

3 Medical Officer, Department of Hematology, BSMMU, Dhaka

4 Assistant Professor, Department of Hematology, BSMMU, Dhaka

5 Professor, Department of Hematology, BSMMU, Dhaka

6 Indoor Medical Officer, Department of Medicine, DMCH, Dhaka

7 Medical Officer, Department of Medicine, BSMMU, Dhaka

Address of Correspondence: Dr.Mujahida Rahman, Medical Officer, Department of Hematology, BSMMU, Dhaka

Bangladesh J Medicine 2014; 25 : 13-16 
Iron deficiency is widely prevalent throughout the world, particularly in developing countries like Bangladesh. Iron deficiency was found in $27.2 \%$ of bthalassemia trait in Northern India ${ }^{5}$. It is often impossible to differentiate between iron deficiency anemia and thalassemia trait either by examining the red cell morphology or the red cell indices.

Under this situation, the present study has been undertaken to find out the pattern of iron status in carriers of hereditary hemoglobin disorders and to determine the presence of co-existing iron deficiency in them. In this way, assessment of iron status of thalassemia trait would assist in decisions regarding therapy with iron ${ }^{5}$.

There are numerous conflicting findings regarding the association of thalassemia trait and iron stores. Some investigators have found normal iron store reflected by measurement of serum ferritin level ${ }^{6}$, others have reported that $b$-thalassemia traits are frequently in positive iron balance and are at high risk of developing iron overload ${ }^{7-9}$. If severe iron overload has been described in a group of patients with thalassemia trait then administration of iron to these cases can actually be proved harmful and produce the complication of iron.

On the other hand, some have found a greater incidence of iron deficiency in thalassemia trait than in the normal population ${ }^{10}$. Iron deficiency is a frequent finding in female thalassemia trait of reproductive age and adequate iron supplementation should be given to these subjects after assessment of iron stores by ferritin measurement ${ }^{6}$.

Raised haemoglobin $\mathrm{A}_{2}$ level is an important diagnostic feature of beta thalassaemia trait. It was demonstrated that co-existing iron deficiency does not interfere with the diagnosis of beta thalassaemia trait based on the raised $\mathrm{Hb} \mathrm{A}_{2}$ level ${ }^{11}$. Contrary to above observation regarding the $\mathrm{Hb} \mathrm{A_{2 }}$ level some investigators reported that there was reduction in $\mathrm{Hb} \mathrm{A}_{2}$ level with iron deficiency even in the presence of beta thalassemia trait 5,12 . In this situation administration of iron to these subjects increases the level of $\mathrm{HbA}_{2}$ and unmasked the diagnosis of beta thalassemia trait.

There is no previous study to explore the iron status in thalassemia trait in Bangladesh. The study was undertaken to determine the prevalence of co-existent iron deficiency and carriers of thalassemia and to develop a strategy for supplementing rational amount of iron to those subjects.

\section{Materials and Methods}

This cross sectional study was carried out in the Department of Hematology, BSMMU, Dhaka from January 2007 to December 2007. All clinically anemic patients attending hematology outpatient department of BSMMU were sent for $\mathrm{CBC}$ with $\mathrm{PBF}$ and those revealing microcytic hypochromic anemia were screened for thalassemia on the basis of clinical history, physical findings and ultimately hemoglobin electrophoresis. Citrate agar gel electrophoresis at alkaline $\mathrm{pH}$ was done. Subjects taking iron preparation or blood transfusion, suffering from acute febrile illness, inflammatory disorders, hematological malignances and liver disease were excluded from the study. A total of 50 anemic patients with carrier state of thalassemia were selected for further investigation. Red cell indices ( $\mathrm{MCV}, \mathrm{MCH}, \mathrm{MCHC})$ and iron profile (S. iron level, S. ferritin, TIBC, Transferrin saturation) were observed among the study subjects. Patients in whom the iron profile showed iron deficiency were compared with those having no iron deficiency. Relevant information was recorded in a preformed data collection sheet. Data were analyzed by using SPSS statistical package version 12 .

\section{Results}

A total 50 subjects with microcytic hypochromic anemia of were selected among whom proportion of male and female were equal. Age range was 16-52 years. Frequency of Iron deficiency was 30.2\% among b-thalassemia trait but none of the $\mathrm{Hb} \mathrm{E}$ trait were iron deficient (Table I \& Fig. 1). The mean age in years of study subjects were $30.38 \pm 9.79$ years. Highest frequency of co-incident iron deficiency was found among the age of 21-30 years (Table II).

Table I

Distribution of the iron deficiency by carriers of thalassemia

\begin{tabular}{lccc}
\hline Iron & \multicolumn{3}{c}{ Inherited hemoglobin disorders } \\
deficiency & $\begin{array}{c}\text { Beta thalassemia } \\
\text { trait }(\%)\end{array}$ & $\begin{array}{c}\text { E trait } \\
(\%)\end{array}$ & $\begin{array}{c}\text { Total } \\
(\%)\end{array}$ \\
\hline Present & $13(30.2)$ & $0(.0)$ & $13(26.0)$ \\
Absent & $30(69.8)$ & $7(100.0)$ & $37(74.0)$ \\
\hline Total & $43(100.0)$ & $7(100.0)$ & $50(100.0)$ \\
\hline
\end{tabular}

Table II

Distribution of the study subjects by age

\begin{tabular}{lcc}
\hline Age (in year) & Frequency(n) & Percent $(\%)$ \\
\hline$\leq 20$ & 7 & 14.0 \\
$21-30$ & 25 & 50.0 \\
$31-40$ & 8 & 16.0 \\
$40-50$ & 8 & 16.0 \\
$>50$ & 2 & 4.0 \\
Total & 50 & 100.0 \\
Mean \pm SD (Range) & $30.38 \pm 9.79$ & $(16-52)$ \\
\hline
\end{tabular}


Table III

Distribution of $\mathrm{Hb}, \mathrm{MCV}, \mathrm{MCH}, \mathrm{MCHC}$, S.Iron, TIBC, S. Ferritin, Transferrin saturation among study subjects.

\begin{tabular}{|c|c|c|c|c|}
\hline \multirow{2}{*}{$\overline{\mathrm{Hb}(\mathrm{g} / \mathrm{dl})}$} & \multirow{2}{*}{$\begin{array}{l}\text { Mean } \\
\text { With iron deficiency }\end{array}$} & \multicolumn{2}{|c|}{ SD } & \multirow{2}{*}{$\frac{\text { p value* }}{0.001}$} \\
\hline & & 6.88 & 1.17 & \\
\hline & Without iron deficiency & 10.23 & 1.47 & \\
\hline \multirow[t]{2}{*}{$\operatorname{MCV}$ (f1) } & With iron deficiency & 51.54 & 5.24 & 0.001 \\
\hline & Without iron deficiency & 72.05 & 5.24 & \\
\hline \multirow[t]{2}{*}{ MCH (pg) } & With iron deficiency & 15.15 & 2.21 & 0.001 \\
\hline & Without iron deficiency & 21.65 & 2.69 & \\
\hline \multirow[t]{2}{*}{ MCHC (g/d1) } & With iron deficiency & 29.69 & 2.21 & 0.923 \\
\hline & Without iron deficiency & 29.78 & 2.81 & \\
\hline
\end{tabular}

*t test was done to measure the level of significance

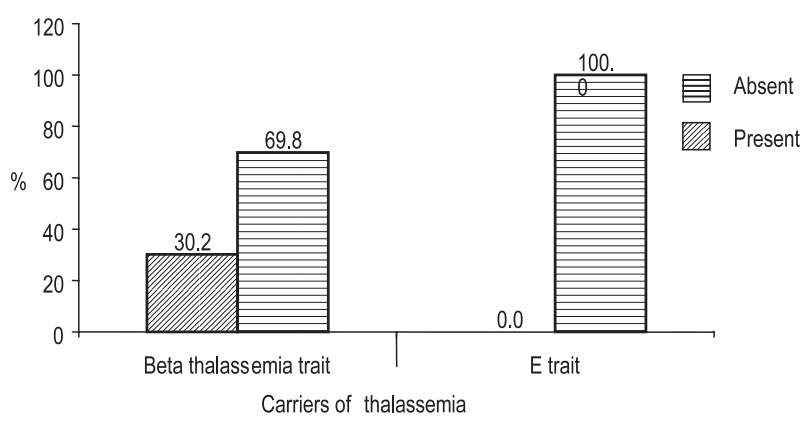

Fig.-1: Bar chart of the iron deficiency among the carriers of thalassemia

A statistically significant differences regarding the means of $\mathrm{Hb}, \mathrm{MCV}, \mathrm{MCH}, \mathrm{MCHC}$ was found among the study subjects without iron deficiency and the subjects with iron deficiency ( $p$ value $=0.001$ ) [Table III]. All these parameters found higher among the iron rich people than the iron deficient people.

\section{Discussion}

b-thalassemia trait produces mild ineffective erythropoiesis associated with increased iron absorption. It might therefore be expected to give some degree of protection against iron deficiency, but this might not be true in all the cases. Most of the subjects with thalassemia trait produce microcytic hypochromic blood picture, but this change might not be solely due to subnormal production of globin chains. A good proportion of such cases have iron deficiency that contributes to the blood picture and they require iron supplementation to replenish the deficient iron status to raise their $\mathrm{Hb}$ level. Earlier diagnosis of the $\mathrm{Hb}$ disorders and restriction of iron intake by the first physicians might play a major role for this clinical entity. On the basis of red cell morphology it is often impossible to differentiate iron deficiency and thalassemia trait and co-existence of both.

Iron deficiency was found in a quarter of traits, mostly among the age group 21-30 years.

A statistically significant mean difference of $\mathrm{Hb}$ was found indicating study subjects without iron deficiency had higher (10.23 g/d1) Hb level than subjects with concurrent iron deficiency $(6.88 \mathrm{~g} / \mathrm{dl})$. The mean MCV (72.05 fl vs. $51.54 \mathrm{fl})$ and $\mathrm{MCH}(21.65$ pg vs. $15.15 \mathrm{pg}$ ) were also high in the group without iron deficiency and statistically significant higher mean difference was found in relation to iron deficient group ( $\mathrm{p}=0.001)$ (Table III). Same were observed in other study ${ }^{13}$.

The finding of the study shows that in a considerable number of subjects 13 (26\%) of beta thalassemia trait with low level of $(<12 \mu \mathrm{g} / 1)$ of serum ferritin indicating co-existing iron deficiency. On the other hand, among the study group, 7 patients had $\mathrm{Hb} \mathrm{E}$ trait and their serum ferritin level were found normal.

This finding of the present study is also consistent with other study which was carried out on British Asian children 13, 14. The co-existence might be due to different gastrointestinal disorders, chronic blood loss due to different helminthes infestation which is very common in Bangladesh. A poor bioavailability and low iron content of food, late weaning, low birth weight baby, pre-existing iron deficiency should come under consideration of co-existing iron deficiency in context of Bangladesh. Last of all, fear of iron overload and its complications may persuade the physicians and their thalassemic patients to practice a strict iron-free diet from the time of diagnosis.

\section{Conclusion:}

The phenotypic expression of thalassemia trait is very diverse and it has been thought that iron absorption 
in these individuals is increased. But this observation does not always exclude iron deficiency to have a contribution to anemia among the thalassemia trait. Clinical iron deficiency anemia may frequently coexist with beta thalassemia trait and iron supplementation is invariably needed in deficient subjects. So, co-existing iron deficiency should always come under consideration among anemic individuals with thalassemia trait in the context of low socioeconomic condition of Bangladesh.

\section{References:}

1. Hoffbrand AV, Catovsky D, Tuddenham EGD. Post graduate Haematology. $5^{\text {th }}$ ed, Blackwell publishing Limited, 2005; 85-89.

2. Thalassaemia International Federation. Guidelines for the clinical management of thalassaemia. 2008:1-5.

3. Greer J, Foester J, Glader B. Wintrobe's Clinical Haematology, $11^{\text {th }}$ ed.2004; 42:1319.

4. Khan MA. Thalassaemia in Bangladesh. DS (Child) HJ 1999; 15:42-44.

5. Sikka M, Madan Sharma S. Haematological parameters and $\mathrm{Hb}$ A2 levels in beta thalassaemia trait with coincident iron deficiency. Indian $\mathrm{J}$ Pathol Microbiol 1998; 41: 309-13.

6. Economidu J, Augustaki O, Parcha S. Assessment of iron stores in subjects heterozygous for $§$ thalassaemia based on serum ferritin levels. Acta Haematol 1980; 64: 205-08.

7. Fargion S, Piperno A, Taddiei. Iron overload in subjects with b-thalassaemia trait. Role of Idiopathic Haemochromatosis Gene. Br J Haematol.1985; $61: 487$.

8. Musumeci S, Romeo MA, Di Gergorio F. Iron status in Sicilian subjects with thalassaemia trait. Birth defects.1988; 23:19-24.

9. White HM, Richards R, Sky GJ. Iron state in Alpha and beta thalassaemia trait. J Clin Pathol 1986; 39:256-259.

10. Kattamis C, Lagos P, Metaxotou-Mavromati A. Serum iron and unsaturated iron binding capacity in the $§$ thalassaemia trait: Their relation to the levels of HbA2 and F. J Med Genet 1972; 9:154.

11. Kurlekar N, Mehta BC. HbA2 levels in iron deficiency on anaemia. Indian Med Res 191; 73:77.

12. Josephson AM, Masri MS, Singer L. Starch block electrophoretic studies of human $\mathrm{Hb}$ solution. Results in cord blood, thalassaemia and other haematological disorders; comparison with Tiselius electrophoresis. Blood 1958; 13:546.

13. Hinchliffe RF, Lilleyman JS. Frequency of coincident iron deficiency and b-thalassaemia trait in British Asian Children. J Clin Pathol 1995; 48:594-595.

14. B.C. Mehta and B.G.Pandya. Iron status of Beta thalassaemia carriers. American Journal of Haematology.1987; 24:137-141. 